\title{
ChemComm
}

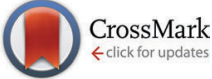

Cite this: Chem. Commun., 2015, 51, 9698

Received 11th April 2015

Accepted 6th May 2015

DOI: $10.1039 / \mathrm{c5cc03013g}$

www.rsc.org/chemcomm

\section{Crystal-surface-induced simultaneous synthesis and hierarchical morphogenesis of conductive polymers $\dagger$}

\author{
Kento Kuwabara, Yuya Oaki, ${ }^{*}$ Ryo Muramatsu and Hiroaki Imai*
}

\begin{abstract}
The surface of oxidant crystals facilitates the simultaneous synthesis and morphogenesis of conductive polymer materials. Oxidant crystals as a condensed phase of the oxidative agent induce the formation of the conductive polymer nanoparticles and their accumulated films.
\end{abstract}

Morphology control of materials plays an important role in tuning of their properties. ${ }^{1}$ In general, it is not easy to achieve simultaneous synthesis and hierarchical morphogenesis of conductive polymers because of their insolubility and low processability. Herein we report on the direct synthesis and morphology control of conductive polymers on the surface of inorganic oxidant crystals with diffusion of monomer vapors, such as pyrrole (Py), thiophene (Tp), and aniline (Ani) derivatives. Morphologies of crystalline inorganic materials are controlled by tuning of synthetic conditions for reaction and crystal growth. ${ }^{2,3}$ Rationally designed organic molecules form self-organized functional materials. ${ }^{4}$ However, morphology control of conductive polymers in multiple length scales is not fully studied in previous reports. In general, templates are used for morphogenesis of materials, such as conductive polymers. ${ }^{5-9}$ Self-assembled molecules serve as templates for generation of complex shapes in a nanometer scale. ${ }^{7}$ Porous materials mediate morphology replication from the original materials to polymers through infiltration and polymerization of monomers in the pore space. ${ }^{8}$ In our previous reports, ${ }^{9}$ the hierarchical morphologies consisting of the oriented unit nanocrystals, as observed in biominerals, were replicated to conductive polymers through polymerization in the nanoscale interspace between the unit crystals. Although templates facilitate generation of a variety of shapes, morphology variety of the replicated materials is limited to that of the original templates. Our challenge here is to develop a new approach for

Department of Applied Chemistry, Faculty of Science and Technology,

Keio University, 3-14-1 Hiyoshi, Kohoku-ku, Yokohama 223-8522, Japan.

E-mail: oakiyuya@applc.keio.ac.jp, hiroaki@applc.keio.ac.jp

$\dagger$ Electronic supplementary information (ESI) available: Experimental methods, microscopy images and spectroscopic data for the other conductive polymers, spectroscopic data to study the formation mechanisms, the reference samples and data of the electrochemical properties. See DOI: $10.1039 / \mathrm{c} 5 \mathrm{cc} 03013 \mathrm{~g}$ the simultaneous synthesis and hierarchical morphogenesis of conductive polymers.

Polyolefine for practical uses, such as polyethylene and polypropylene, is produced from monomer vapors on the solid surface of the catalyst powder. ${ }^{10}$ In the present work, inspired by the method, oxidative polymerization of heteroaromatic monomers is performed on the surface of oxidant crystals with supply of monomer vapors (Fig. 1). Vapor-phase polymerization is studied in a couple of systems. ${ }^{11-16}$ In the current study, the surface of the oxidant crystals is used for polymerization of the monomers supplied from the vapor phase. The conductive polymers are directly synthesized and grown on the crystal surface. In general, both monomers and oxidative agents are supplied from the dilute phases, such as vapor and solution. ${ }^{11-17}$ In the current study, the oxidant crystals as the condensed phase supply the oxidative agents with high density and rate on the solid surface. The oxidative agents are continuously supplied to the monomers adsorbed on the surface of the oxidant crystals during polymerization. Therefore, the simultaneous multiple formation of the polymer nanoparticles and their subsequent growth are achieved on the surface of the oxidant crystals.

In previous studies, monomer vapors are used for the preparation of conductive polymers, such as vapor phase polymerization and oxidative chemical vapor deposition methods. ${ }^{13-15}$ In the vaporphase polymerization method, ${ }^{14}$ the polymerization of heteroaromatic monomers proceeds in polymer matrices containing oxidative agents by diffusion of monomer vapors. As for oxidative

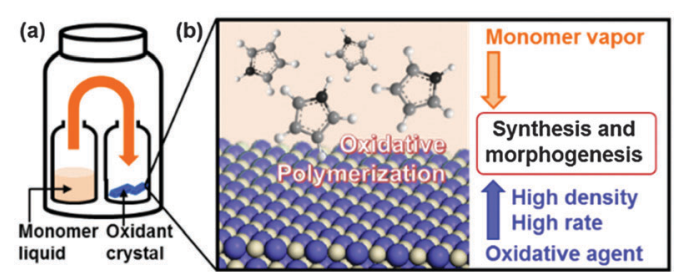

Fig. 1 Schematic illustrations of crystal-surface-induced synthesis and morphogenesis of conductive polymers. (a) Experimental set-up. (b) Polymerization reaction on the surface of the oxidant crystals. 
chemical vapor deposition, ${ }^{15}$ both vapors of monomers and sublimated oxidative agents produce conductive polymers on substrates under vacuum conditions at high temperature. In our recent report, ${ }^{16}$ coating and morphogenesis of conductive polymers were achieved on a variety of substrates and substances through spontaneous generation of the activated monomers in the vapor phase under low temperature and ambient pressure. In these vapor polymerization methods, substrates and substances serve as the deposition sites. The dense and flat films of conductive polymers are obtained on substrates. It is not easy to achieve the formation of the hierarchical structures without the use of the templates by these previous methods. In general, functional organic materials are assembled on the solid surface, such as the layer-by-layer assembly technique. ${ }^{18}$ In the present work, the solid surface induces the spontaneous formation and growth of conductive polymers. Our intention here is the spontaneous formation of hierarchical structures by combinations of vaporized monomers and solid oxidants. In the present work, the inorganic crystals were used as both a substrate and oxidative agent for polymerization (Fig. 1). The vapors of monomers, such as Ani, Py, and Tp, were supplied to the surface of solid oxidant crystals under low temperature and ambient pressure. On the surface, the oxidative polymerization of the heteroaromatic monomers generated the nanoparticles and their accumulated architectures of conductive polymers. When the oxidant crystals with the sponge morphology were used, the resultant conductive polymer shows the sponge morphology with the hierarchical structures. The hierarchical structures contributed the improvement of the electrochemical properties. The present study shows the potential of a generalizable approach for simultaneous synthesis and morphogenesis of conductive polymers by using solid crystal surfaces.

Fig. 2 shows the synthesis and morphogenesis of polyaniline (PAni) on the surface of polyhedral copper nitrate trihydrate $\left(\mathrm{Cu}\left(\mathrm{NO}_{3}\right)_{2} \cdot 3 \mathrm{H}_{2} \mathrm{O}\right)$ crystals upon exposure of Ani vapor at $60{ }^{\circ} \mathrm{C}$ under ambient pressure. $\ddagger$ Two small glass vessels each containing neat liquid of Ani and oxidant crystals of $\mathrm{Cu}\left(\mathrm{NO}_{3}\right)_{2} \cdot 3 \mathrm{H}_{2} \mathrm{O}$ were put in a large sample bottle (Fig. 1a). The sealed sample bottle was maintained at $60{ }^{\circ} \mathrm{C}$ under ambient pressure for $15 \mathrm{~min}$ to $48 \mathrm{~h}$. The detailed methods are described in the ESI. $\dagger$ The color of $\mathrm{Cu}\left(\mathrm{NO}_{3}\right)_{2} \cdot 3 \mathrm{H}_{2} \mathrm{O}$ crystals was gradually changed from blue to black with an increase in the reaction time (Fig. 2a-d). In the early stage, the nanoparticles less than $100 \mathrm{~nm}$ in size were obtained on the surface of the oxidant crystals (Fig. 2e). The films consisting of the connected and accumulated nanoparticles were formed with an increase in the reaction time after $2 \mathrm{~h}$ (Fig. $2 \mathrm{f}$ and g). The size of the nanoparticles and the thickness of the films were increased up to $c a .100 \mathrm{~nm}$ and $6 \mu \mathrm{m}$ after $48 \mathrm{~h}$, respectively (Fig. $2 \mathrm{~h}$ ). The films were isolated by dissolution of the inorganic salts with immersion in $1 \mathrm{~mol} \mathrm{dm}^{-3}$ hydrochloric acid $(\mathrm{HCl})$. The resultant polymers were assigned to PAni by Fourier-transform infrared (FT-IR) absorption spectroscopy (Fig. 2i). ${ }^{19}$ The resultant PAni was the emeraldine salt containing about $3 \mathrm{wt} \%$ of the remaining copper-related compounds. (Fig. S1 in the $\mathrm{ESI} \dagger)$. The production amount of PAni on the $\mathrm{Cu}\left(\mathrm{NO}_{3}\right)_{2} \cdot 3 \mathrm{H}_{2} \mathrm{O}$ surface is estimated to be $0.604 \mathrm{mg} \mathrm{cm}^{-2}$ on the assumption that the closely-packed nanoparticles provide the film $6 \mu \mathrm{m}$ thickness for $48 \mathrm{~h}$ of the reaction (Fig. 2h). The estimation suggests that an increase in the specific surface area of the oxidant crystals facilitates the
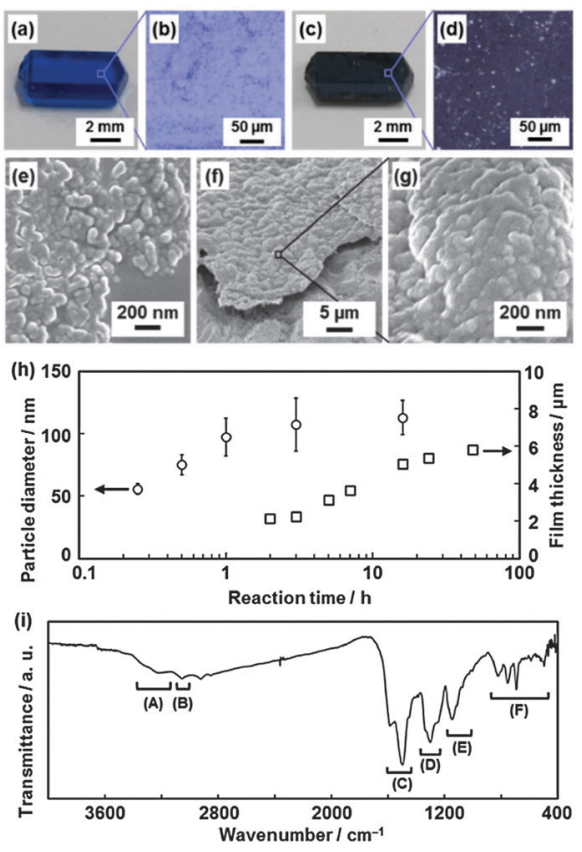

Fig. 2 Synthesis and morphology control of PAni on the surface of $\mathrm{Cu}\left(\mathrm{NO}_{3}\right)_{2} \cdot 3 \mathrm{H}_{2} \mathrm{O}$ crystals. (a-d) Macroscopic appearances (a and c) and optical microscopy images ( $b$ and $d$ ) of the $\mathrm{Cu}\left(\mathrm{NO}_{3}\right)_{2} \cdot 3 \mathrm{H}_{2} \mathrm{O}$ polyhedral crystals before ( $a$ and $b$ ) and after ( $c$ and d) the polymerization. (e) FESEM image of the PAni nanoparticles after the reaction for $1 \mathrm{~h}$. ( $f$ and $g$ ) FESEM images of the PAni films consisting of accumulated nanoparticles after the reaction for $16 \mathrm{~h}$. (h) Time dependent changes of the particle sizes (the circles) and the film thickness (the squares). (i) FT-IR spectrum of the resultant PAni after the reaction of $40 \mathrm{~h}$. The absorption bands $(A-F)$ correspond to the following characteristic vibrations in PAni: ${ }^{19}$ (A) stretching vibration of $\mathrm{N}-\mathrm{H}$, (B) stretching vibration of $=\mathrm{C}-\mathrm{H}$ in the aromatic ring, (C) stretching vibration of $\mathrm{C}=\mathrm{C}$, (D) stretching vibration of $\mathrm{C}-\mathrm{N}$, (E) in-plane bending of $\mathrm{C}-\mathrm{H}$, and (F) out-of-plane bending of $\mathrm{C}-\mathrm{H}$.

improvement of the productivity. In addition, the scale up can be achieved by enlargement of the batch as shown in Fig. 1a.

The present method provides not the dense flat films but the nanoparticles and their accumulated films (Fig. 2e-g). The polymerization was initiated by adsorption of the Ani monomers on the surface of $\mathrm{Cu}\left(\mathrm{NO}_{3}\right)_{2} \cdot 3 \mathrm{H}_{2} \mathrm{O}$ crystals. The polymerization of Ani proceeds at the surface through reduction of the divalent copper ions to the monovalent ones (Fig. S2 in the ESI $\dagger$ ). The PAni nanoparticles are formed and grown on the surface (Fig. 2e). The monomer vapor is diffused to the underlying fresh surface displaying divalent copper ions through the interspace of the nanoparticles. The subsequent PAni nanoparticles are formed on the underlying surface. The formation and growth of the nanoparticles proceed into the inside of the oxidant crystals. In this way, the nanoparticles and their accumulated films are obtained with an increase in the reaction time. The oxidant crystals as the condensed phase of the oxidative agent play important roles for the present scheme. The oxidative agents can be continuously supplied to the monomers with high density and rate to the monomers on the surface. This approach has potential for application in a variety of polymerization reactions by using the crystal surfaces.

The combinations of the monomers and oxidant crystals were changed for application of the present approach (Table 1). 
Table 1 Combinations of the monomers and oxidant crystals

\begin{tabular}{llllll}
\hline & \multicolumn{7}{l}{ Monomers } \\
\cline { 2 - 6 } Oxidant crystals & AN & Py & EDOT & Tp & $3 \mathrm{HT}$ \\
\hline $\mathrm{FeCl}_{3}$ & $+^{a}$ & + & + & + & + \\
$\mathrm{CuBr}_{2}$ & + & + & + & + & $-{ }^{b}$ \\
$\mathrm{CuCl}_{2} \cdot 2 \mathrm{H}_{2} \mathrm{O}$ & + & + & + & - & - \\
$\mathrm{Cu}\left(\mathrm{NO}_{3}\right)_{2} \cdot 3 \mathrm{H}_{2} \mathrm{O}$ & + & + & $\dagger^{c}$ & - & - \\
$\mathrm{Cu}\left(\mathrm{CH}_{3} \mathrm{COO}\right)_{2} \cdot \mathrm{H}_{2} \mathrm{O}$ & $\dagger$ & + & - & - & - \\
$\mathrm{CuSO}_{4} \cdot 5 \mathrm{H}_{2} \mathrm{O}$ & $\dagger$ & + & - & - & - \\
$\mathrm{AgNO}_{3}$ & + & + & + & - & -
\end{tabular}

$a$ “"” the conductive polymers were obtained. ${ }^{b}$ " - " "no deposition was observed on the crystal surface. ${ }^{c}$ " $\uparrow$ " the products were not polymers.

The conductive polymers were obtained from the monomers of Tp, 3,4-ethylenedioxythiophene (EDOT), 3-hexylthiophene (3HT), and Py on the crystal surface of the oxidants (Fig. S3 in the ESI $\dagger$ ). The resultant polymers, such as polythiophene (PTp), poly $(3,4-$ ethylenedioxythiophene) (PEDOT), poly(3-hexylthiophene) (Р3HT), and polypyrrole (PPy), showed the similar morphology variation from the nanoparticles to their accumulated films as observed in PAni (Fig. S4 in the ESI $\dagger$ ). In Table 1, whether or not the conductive polymers are formed is ascribed to the nature of the monomers and oxidant crystals. The resonance stability and electron density of the monomers involve the reactivity. The polymerization reaction is promoted by the monomers with the lower resonance stability. For example, the resonance stabilization energies of Py and $\mathrm{Tp}$ are reported to be $90.4 \mathrm{~kJ} \mathrm{~mol}^{-1}$ and $122 \mathrm{~kJ} \mathrm{~mol}^{-1}$, respectively. ${ }^{20}$ In the present work, Py with the lower resonance stability is polymerized on the surface of all the oxidant crystals (Table 1), while Tp with the higher resonance stability is polymerized only on the crystal surface of iron(III) chloride $\left(\mathrm{FeCl}_{3}\right)$ and copper bromide $\left(\mathrm{CuBr}_{2}\right)$. In addition, substituents of the heteroaromatic monomers vary in the electron density of the ring relevant to the reactivity of oxidative polymerization. These factors including resonance stability and electron density can be represented by the oxidation potentials of the monomers. Vapor pressure of the monomers is another factor related to the reaction rate. The nature of the oxidant crystals also involves the reactivity. The metal cations of the oxidant crystals are reduced with polymerization (Fig. S2 in the ESI $\dagger$ ). As for the oxidant crystals, the reduction potential higher than the oxidation potential of the monomers is required to facilitate the present scheme. The stability of the reduced species and hydration states of the crystals have influences on the reactivity.

The improved electrochemical properties were observed on the conductive polymers by morphology control based on the present method (Fig. 3). Conductive polymers are applied to a supercapacitor with redox reactions. ${ }^{21}$ The morphology control contributes to the improvement of the electrochemical properties. ${ }^{22}$ As shown in Fig. $2 \mathrm{f}$ and $\mathrm{g}$, the films consisting of the accumulated nanoparticles were obtained on the polyhedral crystals of the oxidative agent. If the macroscopic morphologies of oxidant crystals are tuned before polymerization, the macroscopic morphologies of the conductive polymers can be controlled. As a simple model, the micrometer-scale sponge morphology of copper sulfate pentahydrate $\left(\mathrm{CuSO}_{4} \cdot 5 \mathrm{H}_{2} \mathrm{O}\right)$ crystals was prepared by freeze drying (Fig. 3a). The present method is applied to the surface of the oxidant crystals with complex morphologies in a micrometer scale. The freeze-dried $\mathrm{CuSO}_{4} \cdot 5 \mathrm{H}_{2} \mathrm{O}$ crystal was used as a substrate for the synthesis of PPy. The PPy architecture was obtained after dissolution of the copper related compounds by $\mathrm{HCl}$. The sponge morphology of the original $\mathrm{CuSO}_{4} \cdot 5 \mathrm{H}_{2} \mathrm{O}$ crystal was replicated to PPy (Fig. 3b). The assembly of films made up the sponge shape with the pores several micrometers in size (Fig. 3b). The films consisted of the accumulated nanoparticles less than $100 \mathrm{~nm}$ in size (Fig. 3c). The hierarchical structures showed the improved properties of a supercapacitor (Fig. 3d-f). As a reference, the similar PPy films consisting of the nanoparticles without the micrometer-scale sponge shape were prepared on the surface of polyhedral $\mathrm{CuSO}_{4} \cdot 5 \mathrm{H}_{2} \mathrm{O}$ crystals (Fig. S5 in the ESI $\dagger$ ). A commercial fibrous PPy with submicrometer width was used as a reference sample (Fig. S5 in the $\mathrm{ESI} \dagger$ ). The working electrodes were prepared by mixing $80 \mathrm{wt} \% \mathrm{PPy}$ samples, $10 \mathrm{wt} \%$ acetylene black, and $10 \mathrm{wt} \%$ poly(vinylidene fluoride) (PVDF). The electrochemical properties of a supercapacitor were investigated over the potential range of -0.2 to $0.6 \mathrm{Vvs}$. Ag/ $\mathrm{AgCl}$ by chronopotentiometry in an aqueous solution containing $1 \mathrm{~mol} \mathrm{dm}^{-3}$ potassium chloride. The chronopotentiograms show the linear changes of the potential during the charge and discharge processes at the current density of $1 \mathrm{Ag}^{-1}$ and $10 \mathrm{Ag}^{-1}$ (Fig. 3d and e). The electrochemical behavior suggests that the PPy samples serve as a supercapacitor. The specific capacitances were $156 \mathrm{~F} \mathrm{~g}^{-1}$ for
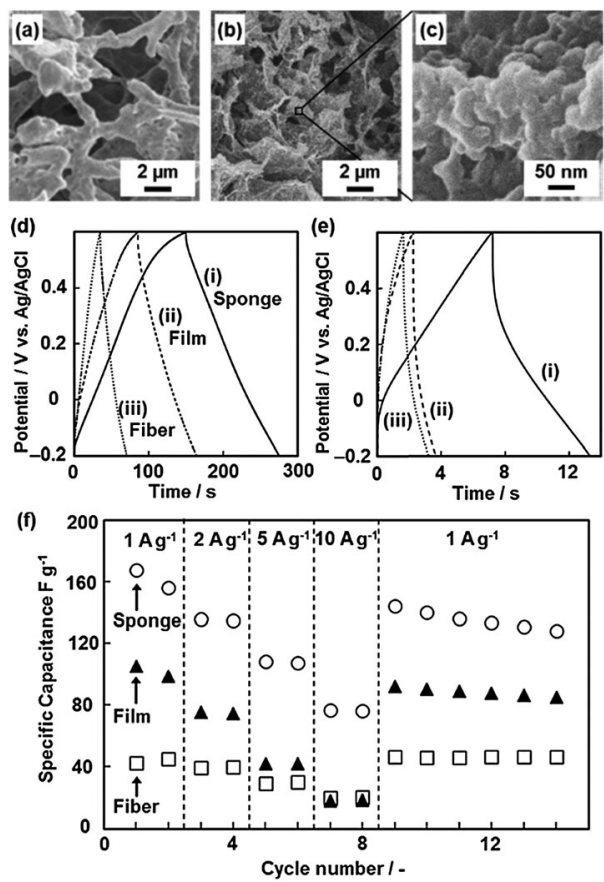

Fig. 3 The PPy sponge with the hierarchical architectures and the electrochemical properties. (a) FESEM images of the porous $\mathrm{CuSO}_{4} \cdot 5 \mathrm{H}_{2} \mathrm{O}$ crystals by freeze drying. ( $b$ and $c$ ) FESEM images of the resultant sponge PPy with the hierarchical structures after dissolution of the inorganic crystals. ( $d$ and e) Chronopotentiograms of the PPy sponge with the hierarchical structures (i), films consisting of the nanoparticles without the sponge shapes (ii), and commercial fibers (iii) at the current density of $1 \mathrm{~A} \mathrm{~g}^{-1}$ (d) and $10 \mathrm{~A} \mathrm{~g}^{-1}$ (e). (f) Relationship between the current density and specific capacitance of the PPy sponge with the hierarchical structures (circles), films consisting of the nanoparticles (triangles), and commercial fibers (squares). 
the PPy sponge with the hierarchical structure, $98.8 \mathrm{~F} \mathrm{~g} \mathrm{~g}^{-1}$ for the films consisting of accumulated nanoparticles, and $44.8 \mathrm{~F} \mathrm{~g} \mathrm{~g}^{-1}$ for the commercial fibers at the current density of $1 \mathrm{~A} \mathrm{~g}^{-1}$ (Fig. 3d). When the current density was changed from $1 \mathrm{~A} \mathrm{~g}^{-1}$ to $10 \mathrm{~A} \mathrm{~g}^{-1}$, the PPy sponge with hierarchical structures showed improved specific capacitance compared to the other reference samples (Fig. 3f and Fig. S6 in the ESI $\dagger$ ). Since the films consisting of the nanoparticles show the higher specific surface area than the commercial fibers, the specific capacitance of the films is higher than that of the fibers. Furthermore, the macroscopic sponge morphology inhibits the aggregation of the films. The smooth diffusion of the electrolytes was achieved on the PPy surface during the redox reaction. Therefore, the PPy sponge with the hierarchical structures showed improved electrochemical properties.

In summary, conductive polymers, such as PAni, PTp, PEDOT, P3HT, and PPy, were synthesized on the surface of the oxidant crystals with diffusion of the monomer vapors under low temperature and ambient pressure. The nanoparticles and their accumulated films were obtained on the surface with changes in the reaction time. Since the solid surface of the oxidant crystals supplies the oxidative agents to the monomers with high density and rate, the simultaneous syntheses and morphogeneses are achieved on the surface. When morphologies of the oxidant crystals were controlled, the hierarchical morphologies of the conductive polymers were tuned. The porous oxidant crystals generated the porous conductive polymers with the hierarchical structures. The improved electrochemical properties were observed on the hierarchically organized conductive polymers. The present concepts can be applied to the synthesis and morphogenesis of a variety of polymer materials by using the solid surface.

This work was partially supported by Grant-in-Aid for Scientific Research (No. 22107010) on Innovative Areas of "Fusion Materials: Creative Development of Materials and Exploration of Their Function through Molecular Control" (No. 2206) (H.I.) from the Ministry of Education, Culture, Sports, Science and Technology, Grant-inAid for Scientific Research for Young Scientist (A, No. 22685022) (Y.O.) from Japan Society of the Promotion of Science, and Iketani Science and Technology Foundation (Y.O.).

\section{Notes and references}

$\$$ The polymerization reaction proceeds at room temperature. In the present work, temperature is increased to promote the reaction with an increase in the vapor pressure.

1 (a) S. Mann, Angew. Chem., Int. Ed., 2000, 39, 3392; (b) M. Antonietti and G. A. Ozin, Chem. - Eur. J., 2004, 10, 28.

2 (a) S. Mann, Nature, 1988, 332, 119; (b) T. Kato, A. Sugawara and N. Hosoda, Adv. Mater., 2002, 14, 869; (c) S.-H. Yu and H. Cölfen, J. Mater. Chem., 2004, 14, 2124; (d) H. Imai, Y. Oaki and A. Kotachi, Bull. Chem. Soc. Jpn., 2006, 79, 1834; (e) A.-W. Xu, Y. Ma and H. Cölfen, J. Mater. Chem., 2007, 17, 415; $(f)$ F. C. Meldrum and H. Cölfen, Chem. Rev., 2008, 108, 4332; $(g)$ N. A. J. M. Sommerdijk and G. de With, Chem. Rev., 2008, 108, 4499; $(h)$ T. Kato, T. Sakamoto and T. Nishimura, MRS Bull., 2010, 35, 127.

3 (a) Y. Oaki and H. Imai, Angew. Chem., Int. Ed., 2005, 44, 6571; (b) Y. Oaki and H. Imai, Small, 2006, 2, 66; (c) Y. Oaki, A. Kotachi, T. Miura and H. Imai, Adv. Funct. Mater., 2006, 16, 1633.

4 (a) T. Kato, N. Mizoshita and K. Kishimoto, Angew. Chem., Int. Ed., 2006, 45, 38; (b) F. J. M. Hoeben, P. Jonkheijm, E. W. Meijer and
P. H. J. Schenning, Chem. Rev., 2005, 105, 1491; (c) J. J. L. M. Comelissen, A. E. Rowan, R. J. M. Nolte and N. A. J. M. Sommerdijk, Chem. Rev., 2001, 101, 4039; (d) M. Li, S. Ishihara, Q. Ji, M. Akada, J. P. Hill and K. Ariga, Sci. Technol. Adv. Mater., 2012, 13, 053001; (e) L. K. Shrestha, Q. Ji, T. Mori, K. Miyazawa, Y. Yamauchi, J. P. Hill and K. Ariga, Chem. - Asian J., 2013, 8, 1662; $(f)$ Y. Yao, H. Dong and W. Hu, Polym. Chem., 2013, 4, 5197.

5 (a) R. A. Caruso and M. Antonietti, Chem. Mater., 2001, 13, 3272; (b) K. J. C. van Bommel, A. Friggeri and S. Shinkai, Angew. Chem., Int. Ed., 2003, 42, 980.

6 (a) H. W. Liang, J. W. Liu, H. S. Qian and S. H. Yu, Acc. Chem. Res., 2013, 46, 1450; (b) A. Thomas, F. Goettmann and M. Antonietti, Chem. Mater., 2008, 20, 738; (c) S. J. Hurst, E. M. Payne, L. Qin and C. A. Mirkin, Angew. Chem., Int. Ed., 2006, 45, 2672.

7 (a) T. L. Kelly and M. O. Wolf, Chem. Soc. Rev., 2010, 39, 1526; (b) K. Sada, M. Takeuchi, N. Fujita, M. Numata and S. Shinkai, Chem. Soc. Rev., 2007, 36, 415.

8 (a) T. Bein and P. Enzel, Angew. Chem., Int. Ed. Engl., 1989, 28, 1692; (b) E. Ruiz-Hitzky, Adv. Mater., 1993, 5, 334; (c) C. R. Martin, Science, 1994, 266, 1961; (d) D. J. Cardin, Adv. Mater., 2002, 14, 553; (e) K. Tajima and T. Aida, Chem. Commun., 2000, 2399; (f) S. Horike, S. Shimomura and S. Kitagawa, Nat. Chem., 2009, 1, 695; $(g)$ T. Uemura, N. Yanai and S. Kitagawa, Chem. Soc. Rev., 2009, 38, 1228.

9 (a) Y. Oaki, M. Kijima and H. Imai, J. Am. Chem. Soc., 2011, 133, 8594; (b) M. Kijima, Y. Oaki, Y. Munekawa and H. Imai, Chem. Eur. J., 2013, 19, 2284; (c) Y. Munekawa, Y. Oaki and H. Imai, Langmuir, 2014, 30, 3236; (d) Y. Munekawa, Y. Oaki, K. Sato and H. Imai, Nanoscale, 2015, 7, 3466; (e) K. Sato, Y. Oaki and H. Imai, Chem. Commun., 2015, 51, 7919.

10 H. Sinn and W. Kaminsky, Adv. Organomet. Chem., 1980, 18, 99.

11 (a) H. Reiss, Acc. Chem. Res., 1997, 30, 297; (b) M. S. El-Shall, Acc. Chem. Res., 2008, 41, 783.

12 (a) J. A. Lipton-Duffin, J. A. Miwa, M. Kondratenko, F. Cicoira, B. G. Sumpter, V. Meunier, D. F. Perepichka and F. Rose, Proc. Natl. Acad. Sci. U. S. A., 2010, 107, 11200; (b) L. Lafferentx, V. Eberhardt, C. Dri, C. Africh, G. Comelli, F. Esch, S. Hecht and L. Grill, Nat. Chem., 2012, 4, 215; (c) K. Onodera, C. Tanioku and A. Matsumoto, ACS Appl. Mater. Interfaces, 2012, 4, 2280.

13 (a) D. Bhattacharyya, R. M. Howden, D. C. Borrelli and K. K. Gleason, J. Polym. Sci., Part B: Polym. Phys., 2012, 50, 1329; (b) A. M. Coclite, R. M. Howden, D. C. Borrelli, C. D. Petruczok, R. Yang, J. L. Yagüe, A. Ugur, N. Chen, S. Lee, W. J. Jo, A. Liu, X. Wang and K. K. Gleason, Adv. Mater., 2013, 25, 5392.

14 (a) T. Ojio and S. Miyata, Polym. J., 1986, 18, 95; (b) A. Mohammadi, M. A. Hasan, B. Liedberg, I. Lundstrom and W. R. Salaneck, Synth. Met., 1986, 14, 189; (c) J. Kim, E. Kim, Y. Won, H. Lee and K. Suh, Synth. Met., 2003, 139, 485; (d) B. Winther-Jensen and K. West, Macromolecules, 2004, 37, 4538; (e) J. Kim, M. Kwon, Y. Min, S. Kwon and D. W. Ihm, Adv. Mater., 2007, 19, 3501; (f) Y. Oaki, R. Muramatsu and H. Imai, Polym. J., 2015, 47, 183.

15 (a) J. P. Lock, S. G. Im and K. K. Gleason, Macromolecules, 2006, 39, 5326; (b) H. Bai, C. Li, F. Chen and G. Shi, Polymer, 2007, 48, 5259.

16 R. Muramatsu, Y. Oaki, K. Kuwabara, K. Hayashi and H. Imai, Chem. Commun., 2014, 50, 11840.

17 (a) K. Yoshino, S. Hayashi and R. Sugimoto, Jpn. J. Appl. Phys., 1984, 23, L899; (b) R. E. Myers, J. Electron. Mater., 1986, 15, 61; (c) T. Nakajima and T. Kawagoe, Synth. Met., 1989, 28, C629; (d) A. Malinauskas, Polymer, 2001, 42, 3957.

18 (a) K. Ariga, Y. Yamauchi, G. Pydzek, Q. Ji, Y. Yonamine, K. C. W. Wu and J. P. Hill, Chem. Lett., 2014, 43, 36; (b) R. R. Costa and J. F. Mano, Chem. Soc. Rev., 2014, 43, 3453.

19 E. Dmitrieva and L. Dunsch, J. Phys. Chem. B, 2011, 115, 6401.

20 F. Klages, Chem. Ber., 1949, 82, 216.

21 (a) G. A. Snook, P. Kao and A. S. Best, J. Power Sources, 2011, 196, 1; (b) A. Rudge, J. Davey, I. Raistrick, S. Gottesfeld and J. P. Ferraris, J. Power Sources, 1994, 47, 89.

22 (a) K. A. Noh, D. W. Kim, C. S. Jin, K. H. Shin, J. H. Kim and J. M. Ko, J. Power Sources, 2003, 124, 593; (b) Y. Han, X. Qing, S. Ye and Y. Lu, Synth. Met., 2010, 160, 1159; (c) K. Wang, J. Huang and Z. Wei, J. Phys. Chem., 2010, 114, 8062. 